\title{
Comparative Thermal Degradation Behaviors and Kinetic Mechanisms of Typical Hardwood and Softwood in Oxygenous Atmosphere
}

\author{
Xiaokang Xu, Renming Pan and Ruiyu Chen *
}

check for updates

Citation: Xu, X.; Pan, R.; Chen, R. Comparative Thermal Degradation Behaviors and Kinetic Mechanisms of Typical Hardwood and Softwood in Oxygenous Atmosphere. Processes 2021, 9, 1598. https://doi.org/ $10.3390 /$ pr9091598

Academic Editor: Jorge Cunha

Received: 18 August 2021

Accepted: 2 September 2021

Published: 6 September 2021

Publisher's Note: MDPI stays neutral with regard to jurisdictional claims in published maps and institutional affiliations.

Copyright: (c) 2021 by the authors. Licensee MDPI, Basel, Switzerland. This article is an open access article distributed under the terms and conditions of the Creative Commons Attribution (CC BY) license (https:/ / creativecommons.org/licenses/by/ $4.0 /)$.
School of Chemistry and Chemical Engineering, Nanjing University of Science and Technology, Nanjing 210094, China; xiaokangxu@njust.edu.cn (X.X.); 12016042@njust.edu.cn (R.P.)

* Correspondence: crynjust@njust.edu.cn; Tel.: +86-025-8430-3159

\begin{abstract}
In order to utilize woody biomass effectively for bioenergy and chemical feedstocks, the comparative thermal degradation behaviors and kinetic mechanisms of typical hardwood (beech wood) and softwood (camphorwood) were studied at various heating rates in air. The KissingerAkahira-Sunose approach combined with the Coats-Redfern approach was employed to estimate the kinetic triplet. Softwood degradation began and ended at lower temperatures than hardwood. Compared with softwood, the maximal reaction rate of hardwood was greater and occurred in the higher temperature region. Two decomposition regions were determined by the variation of activation energy, and the dividing point was $\alpha=0.6$ and $\alpha=0.65$ for hardwood and softwood, respectively. Moreover, the average activation energy of hardwood was larger than that of softwood during the whole decomposition process. The thermal degradation process occurring in region 1 was dominated by the Avrami-Erofeev and 3D diffusion models for hardwood and softwood, respectively. Furthermore, the kinetic modeling results showed good consistency between the experimental and simulated curves under $5,15,20$, and $40 \mathrm{~K} / \mathrm{min}$. It is noted that the thermogravimetric experimental profile under $20 \mathrm{~K} / \mathrm{min}$ was not used for estimating the kinetic triplet. Besides, the combustion performance of hardwood is superior to softwood under the same external conditions (heating rate and atmosphere).
\end{abstract}

Keywords: thermal degradation; woody biomass; bioenergy; renewable energy; thermogravimetric analysis

\section{Introduction}

In recent decades, the rapid development of industry is driven by the consumption of a large number of energy resources, mainly fossil energy. The large consumption of fossil energy will lead to energy shortages or even energy crisis, and cause serious air pollution and climate change [1-3]. Since the industrial revolution, the concentration of carbon dioxide in the atmosphere has increased by nearly 30\% [4], which is widely considered to be the main cause of the greenhouse effect [5]. The biomass utilization for bioenergy can help to reduce the emission of greenhouse gases and other toxic and harmful gases [6,7], and reduce the dependence of social development on fossil energy [8,9]. As a representative renewable biomass, woody biomass is anticipated to take on an increasingly significant role in the production of bioenergy (such as biochar and biogas) and chemical feedstocks $[10,11]$.

Combustion, as a simple and effective thermochemical conversion technology for solid materials' utilization [12-14], is widely used in heat and electric energy production [15,16]. The combustion of solid materials involves a series of complex redox reactions, and it is mainly affected by the external factors [17-19] (such as heating rate and temperature) and internal factors $[20,21]$ (compositions of solid materials). It has been widely reported that woody biomass is mainly composed of hemicellulose, cellulose, and lignin [22-24]. The structure characteristics and physicochemical properties of these three compositions have 
a great effect on the thermal degradation behaviors of wood $[25,26]$. Woody biomass can be divided into two broad categories, containing hardwood and softwood [12], and the contents of the three main components (hemicellulose, cellulose, and lignin) in these two categories are quite different.

In order to reveal the differences in thermal decomposition characteristics and kinetics between hardwood and softwood, many studies have been carried out. Ding et al. [27] focused on the thermal decomposition characteristics and kinetic mechanisms of hardwood and softwood by thermogravimetric analysis in nitrogen. The obtained activation energy of softwood was greater than that of hardwood during the whole pyrolysis process, and the kinetic mechanisms for both hardwood and softwood can be summed up as a diffusion mechanism followed by a reaction order mechanism. Yao et al. [28] calculated the apparent activation energy of hardwood and softwood in nitrogen atmosphere, and the mean values were approximately 155 and $160 \mathrm{~kJ} / \mathrm{mol}$ for hardwood and softwood, respectively. Zadeh et al. [29] conducted the pyrolysis experiments and characterized the products generated from hardwood and softwood lignin in nitrogen. The results showed that the bio-oil and biochar yields of softwood lignin were higher than hardwood lignin, while the gas yield of softwood lignin was lower than hardwood lignin. Moreover, Asmadi et al. [30] identified the pyrolysis behaviors of hardwood and softwood in nitrogen and showed that hardwood formed more volatiles (tar) instead of char in the primary pyrolysis stage, and the tar-to-gas conversion rates for hardwoods in the secondary reaction stage were smaller than those of softwood. Gronli et al. [31] studied the thermal decomposition characteristics of 4 types of hardwood and 5 types of softwood in nitrogen and indicated that the hardwood degradation initiated at higher temperatures and the degradation regions of hemicellulose and cellulose were narrower compared with those of softwood.

According to the above-mentioned literature, the differences of thermal decomposition behaviors and kinetics between hardwood and softwood in inert atmosphere do exist and have been revealed. It should be noted that the thermal degradation characteristics, activation energy, and kinetic mechanisms of woody biomass under oxidative atmosphere are quite diverse from those under inert atmosphere. In fact, the thermal degradation of solid materials in oxidizing atmosphere is more complicated because the presence of oxidants (air, oxygen, etc.) will produce heterogeneous reactions between oxygen and solid reactants and homogeneous reactions between oxygen and volatiles [27,32-34]. However, to our best knowledge, there are significantly few studies focusing on the differences of the thermal degradation characteristics, kinetic parameters, and kinetic mechanisms between hardwood and softwood under air atmosphere to date.

In our work, the thermal degradation behaviors and kinetic mechanisms of typical hardwood (beech wood) and softwood (camphorwood) were investigated by employing a thermogravimetric analyzer at multiple heating rates in air. The Kissinger-AkahiraSunose $[35,36]$ approach was employed to attain the apparent activation energy and the Coats-Redfern [37] approach was used for estimating the kinetic mechanisms. In addition, the kinetic modeling for hardwood and softwood decomposition was also conducted in this work.

\section{Materials and Methods}

\subsection{Materials}

Beech wood has beautiful color and texture, as well as high hardness, which is often used in furniture, wooden doors, floors, and handicrafts. In addition, beech wood also has the advantages of good load-bearing performance and good compression resistance, which is often used in shipbuilding, construction, and bridges. Beech wood (Fagus sylvatica) is selected as the representative hardwood in the present study. Camphorwood, as used before [38], is considered as the typical softwood, which is used in the present work. Beech wood and camphorwood were sampled from Europe and China, respectively. All the wood samples used in the experiment are the center layers of wood. Before the thermogravimetric experiment, the beech wood and camphorwood were first pulverized into sawdust with 
a mill, and then sawdust with particle size in the range of $0.154-0.2 \mathrm{~mm}$ was screened out with 75- and 100-mesh screens as the experimental samples. Finally, the sawdust was placed in the oven and dried at $378.15 \mathrm{~K}$ for $24 \mathrm{~h}$ to completely remove the free water.

\subsection{Thermogravimetric Experiments}

The comparison of the thermal degradation behaviors between beech wood and camphorwood was conducted by a thermogravimetric analyzer (SDTA 851E) at 5, 15, 20, and $40 \mathrm{~K} / \mathrm{min}$ under air atmosphere. In each test, the specimen mass was approximately $5 \mathrm{mg}$, and was heated from 300 to $1000 \mathrm{~K}$. Air was used for the tests at a flow rate of $60 \mathrm{~mL} / \mathrm{min}$.

\subsection{Kinetic and Thermodynamic Analyses}

The integral approaches were adopted for estimating the kinetic triplet during the thermal decomposition process of beech wood and camphorwood. The kinetic equations can be expressed as follows:

$$
\frac{d \alpha}{d t}=k(T) f(\alpha)
$$

where $\alpha$ is the conversion degree, $t$ is the reaction time and $T$ is the reaction temperature, $k(T)$ is the reaction rate constant, and $f(\alpha)$ is the function of the kinetic mechanism. $\alpha$ and $k(T)$ can be thus obtained as:

$$
\alpha=\left(m_{0}-m_{t}\right) /\left(m_{t}-m_{\infty}\right)
$$

where $m_{0}, m_{t}$, and $m_{\infty}$ are the initial, actual, and final masses of the specimens, respectively.

Based upon the Arrhenius equation, $k(T)$ can be described as the following expression:

$$
k(T)=A \exp \left(-\frac{E_{\alpha}}{R T}\right)
$$

where $A$ and $E_{\alpha}$ are the pre-exponential factor and activation energy respectively, and $R$ is the universal gas constant $(8.314 \mathrm{~J} /(\mathrm{mol} \cdot \mathrm{K}))$.

A constant heating rate $(\beta=d T / d t)$ was performed in a non-isothermal reaction process. Thus, Equation (1) can be rewritten as follows according to Equation (3):

$$
\frac{d \alpha}{d T}=\frac{A}{\beta} \exp \left(-\frac{E_{\alpha}}{R T}\right) f(\alpha)
$$

The following equation can be obtained by integrating the two ends of Equation (4):

$$
g(\alpha)=\int_{0}^{\alpha} \frac{d \alpha}{f(\alpha)}=\frac{A}{\beta} \int_{0}^{T_{\alpha}} \exp \left(-\frac{E_{\alpha}}{R T}\right) d T=\frac{A E_{\alpha}}{\beta R} \int_{y_{\alpha}}^{\infty} \frac{\exp (-y)}{y^{2}} d y=\frac{A E_{\alpha}}{\beta R} p(y)
$$

where $g(\alpha)$ is the function of the kinetic mechanism in its integral form.

Model-free methods (such as Kissinger-Akahira-Sunose [35,36]) can obtain the accurate activation energy, but cannot attain the pre-exponential factor and kinetic mechanism. Model-matching methods (such as Coats-Redfern [37]) are usually adopted to calculate the pre-exponential factor and activation energy with one certain kinetic model [39]. In this work, the KAS method coupled with the CR method was used for estimating the kinetic triplet.

\subsubsection{Kissinger-Akahira-Sunose Approach}

The KAS approach $[35,36]$ is one integral approach and can be expressed as below:

$$
\ln \left(\frac{\beta}{T_{\alpha}^{2}}\right)=\ln \left(\frac{A_{\alpha} R}{E_{\alpha} g(\alpha)}\right)-\frac{E_{\alpha}}{R T_{\alpha}}
$$


The same $\alpha$ is chosen at different heating rates, so that the linear relationship occurs between $\ln \left(\beta / T_{\alpha}{ }^{2}\right)$ and $1 / T$, then $E_{\alpha}$ values are acquired from its slope of $-E_{\alpha} / R$.

\subsubsection{Coats-Redfern Approach}

The CR approach [37] is one popular model-fitting approach for estimating the kinetic mechanisms and parameters $(E$ and $A)$. Based upon an asymptotic approximation $R T / E_{\alpha} \rightarrow 0$, this approach can be expressed as follows:

$$
\ln \left(\frac{g(\alpha)}{T_{\alpha}^{2}}\right)=\ln \left(\frac{A_{\alpha} R}{\beta E_{\alpha}}\right)-\frac{E_{\alpha}}{R T_{\alpha}}
$$

$E$ and $A$ can be obtained from the slope and intercept of the plots $\left(\ln \left(g(\alpha) / T_{\alpha}{ }^{2}\right)\right.$ versus $1 / T)$. Table 1 lists the various functions of kinetic mechanisms for the thermal decomposition of solid materials [40-43].

Table 1. Kinetic models/mechanisms.

\begin{tabular}{|c|c|c|c|}
\hline No. & $g(\alpha)$ & $f(\alpha)$ & Kinetic Mechanism \\
\hline \multicolumn{4}{|c|}{ 1. Power law } \\
\hline 1 & $\alpha^{3 / 2}$ & $2 / 3 \alpha^{-1 / 2}$ & Nucleation \\
\hline 2 & $\alpha^{1 / 2}$ & $2 \alpha^{1 / 2}$ & Nucleation \\
\hline 3 & $\alpha^{1 / 3}$ & $3 \alpha^{2 / 3}$ & Nucleation \\
\hline 4 & $\alpha^{1 / 4}$ & $4 \alpha^{3 / 4}$ & Nucleation \\
\hline \multicolumn{4}{|c|}{ 2. Reaction order } \\
\hline 5 & $-\ln (1-\alpha)$ & $1-\alpha$ & Assumed random nucleation and its subsequent growth \\
\hline 6 & $(1-\alpha)^{-1}-1$ & $(1-\alpha)^{2}$ & Chemical reaction \\
\hline 7 & $(1-\alpha)^{-2}-1$ & $1 / 2(1-\alpha)^{3}$ & Chemical reaction \\
\hline \multicolumn{4}{|c|}{ 3. Avrami-Erofeev } \\
\hline 8 & {$[-\ln (1-\alpha)]^{2 / 3}$} & $3 / 2(1-\alpha)[-\ln (1-\alpha)]^{1 / 3}$ & Assumed random nucleation and its subsequent growth \\
\hline 9 & {$[-\ln (1-\alpha)]^{1 / 2}$} & $2(1-\alpha)[-\ln (1-\alpha)]^{1 / 2}$ & Assumed random nucleation and its subsequent growth \\
\hline 10 & {$[-\ln (1-\alpha)]^{1 / 3}$} & $3(1-\alpha)[-\ln (1-\alpha)]^{2 / 3}$ & Assumed random nucleation and its subsequent growth \\
\hline 11 & {$[-\ln (1-\alpha)]^{1 / 4}$} & $4(1-\alpha)[-\ln (1-\alpha)]^{3 / 4}$ & Assumed random nucleation and its subsequent growth \\
\hline 12 & {$[-\ln (1-\alpha)]^{2}$} & $1 / 2(1-\alpha)[-\ln (1-\alpha)]^{-1}$ & Assumed random nucleation and its subsequent growth \\
\hline 13 & {$[-\ln (1-\alpha)]^{3}$} & $1 / 3(1-\alpha)[-\ln (1-\alpha)]^{-2}$ & Assumed random nucleation and its subsequent growth \\
\hline 14 & {$[-\ln (1-\alpha)]^{4}$} & $1 / 4(1-\alpha)[-\ln (1-\alpha)]^{-3}$ & Assumed random nucleation and its subsequent growth \\
\hline \multicolumn{4}{|c|}{ 4. Contracting } \\
\hline 15 & $1-(1-\alpha)^{1 / 2}$ & $2(1-\alpha)^{1 / 2}$ & Contracting cylinder (cylindrical symmetry) \\
\hline 16 & $1-(1-\alpha)^{1 / 3}$ & $3(1-\alpha)^{2 / 3}$ & Contracting sphere (spherical symmetry) \\
\hline \multicolumn{4}{|c|}{ 5. Diffusion } \\
\hline 17 & $\alpha^{2}$ & $1 / 2 \alpha$ & One-dimensional diffusion \\
\hline 18 & $\alpha+(1-\alpha) \ln (1-\alpha)$ & {$[-\ln (1-\alpha)]^{-1}$} & Two-dimensional diffusion \\
\hline 19 & $1-2 / 3 \alpha-(1-\alpha)^{2 / 3}$ & $(3 / 2)\left[(1-\alpha)^{-1 / 3}-1\right]^{-1}$ & Three-dimensional diffusion, cylindrical symmetry \\
\hline 20 & {$\left[(1-\alpha)^{-1 / 3}-1\right]^{2}$} & $(3 / 2)(1-\alpha)^{4 / 3}\left[(1-\alpha)^{-1 / 3}-1\right]^{-1}$ & Three-dimensional diffusion \\
\hline
\end{tabular}

$E_{\alpha}$ and $A$ estimates gained by the above two kinetic approaches are employed to compute the changes in enthalpy $(\Delta H)$, Gibbs free energy $(\Delta G)$, and entropy $(\Delta S)$, expressed as [44]:

$$
\begin{gathered}
\Delta H=E_{\alpha}-R T_{\alpha} \\
\Delta G=E_{\alpha}+R T_{p} \ln \left(\frac{K_{B} T_{p}}{h A}\right) \\
\Delta S=\frac{\Delta H-\Delta G}{T_{p}}
\end{gathered}
$$


where $K_{B}$ is the Boltzmann constant $\left(1.381 \times 10^{-23} \mathrm{~J} / \mathrm{K}\right), h$ is the Plank constant $\left(6.626 \times 10^{-34} \mathrm{~J} \cdot \mathrm{s}\right)$, and $T_{p}$ is peak temperature.

\subsection{Determination of Combustion Characteristic Parameters}

Thermogravimetric experiments can record the mass loss of biomass during the heating process in real time, which is used to draw the TG (mass loss) and DTG (mass loss rate) curves. From these curves, the thermal parameters of the biomass combustion process can be obtained directly, including ignition temperature $\left(T_{\mathrm{i}}\right)$, peak temperature $\left(T_{\max }\right)$, and burnout temperature $\left(T_{\mathrm{b}}\right)$. These parameters reveal the thermal behavior of biomass during the combustion process, and describe the beginning and end of combustion.

As shown in Figure 1, the ignition temperature $\left(T_{\mathrm{i}}\right)$ is defined as follows: Firstly, a vertical line is drawn through the DTG peak point and intersects with the TG curve at point $\mathrm{O}$. Then, the tangent line of the TG curve at point $\mathrm{O}$ is made and intersects with the extension line of the initial horizontal line of the TG curve at point M. Finally, a vertical line is made through point $\mathrm{M}$ to intersect with abscissa at point $\mathrm{N}$, and the corresponding temperature of point $\mathrm{N}$ is the ignition temperature, $T_{\mathrm{i}}$.

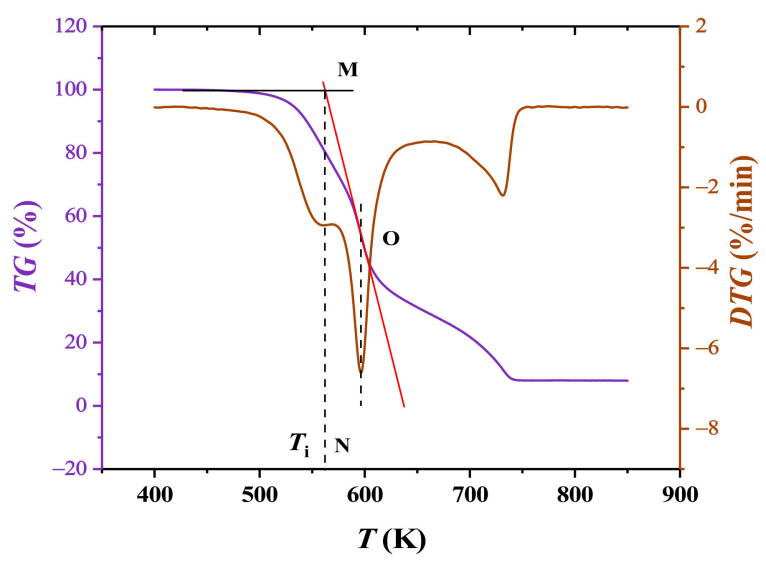

Figure 1. The illustration of ignition temperature $\left(T_{\mathrm{i}}\right)$.

The peak temperature $\left(T_{\max }\right)$ is the temperature at the peak of the DTG curve, while the burnout temperature $\left(T_{\mathrm{b}}\right)$ corresponds to the temperature at the end of the DTG curve ( $1 \%$ mass loss rate).

\section{Results and Discussions}

\subsection{Thermogravimetric Analyses}

Figure $2 \mathrm{a}, \mathrm{b}$ illustrates the reaction rate $(\mathrm{d} \alpha / \mathrm{d} T)$ curves of hardwood (beech wood) and softwood (camphorwood) specimens at 5,15 , and $40 \mathrm{~K} / \mathrm{min}$, respectively. Softwood began to decompose earlier than hardwood, and the thermal degradation process of softwood ended earlier than that of hardwood. There is one shoulder and two distinct peaks on the $\mathrm{d} \alpha / \mathrm{d} T$ curves. The hardwood shoulder occurred at a lower temperature than that of softwood, but the two peaks of hardwood appeared at a higher temperature than that of softwood. Moreover, the shoulder values of hardwood were smaller than those of softwood, but the first peak values of hardwood were larger than those of softwood. In addition, the heating rates had an important influence on the locations and values of the peaks, but it did not change the patterns of the reaction rate curves. The peaks and shoulder moved towards the high-temperature regions for both hardwood and softwood with the elevated heating rate. The reaction rate value of the shoulder rarely varied with the heating rate, and the first peak value declined with the heating rate while the second peak value first increased and then decreased with the heating rate. It is noted that there is an obvious "shoulder" region for softwood at a lower heating rate compared with that at a higher heating rate. Figure $2 c, d$ presents the curves of conversion degree, $\alpha$, under 
multiple heating rates for beech and camphorwood, respectively. Moreover, the detailed information about the decomposition characteristics for hardwood and softwood are listed in Table 2. At the same heating rate, the shoulder of hardwood appeared earlier than that of softwood, while the two peaks appeared later. To further show the differences between the two types of wood, the $\mathrm{d} \alpha / \mathrm{d} T$ curves of beech and camphorwood under 5 and $40 \mathrm{~K} / \mathrm{min}$ are comparatively presented in Figure $3 a, b$, respectively.
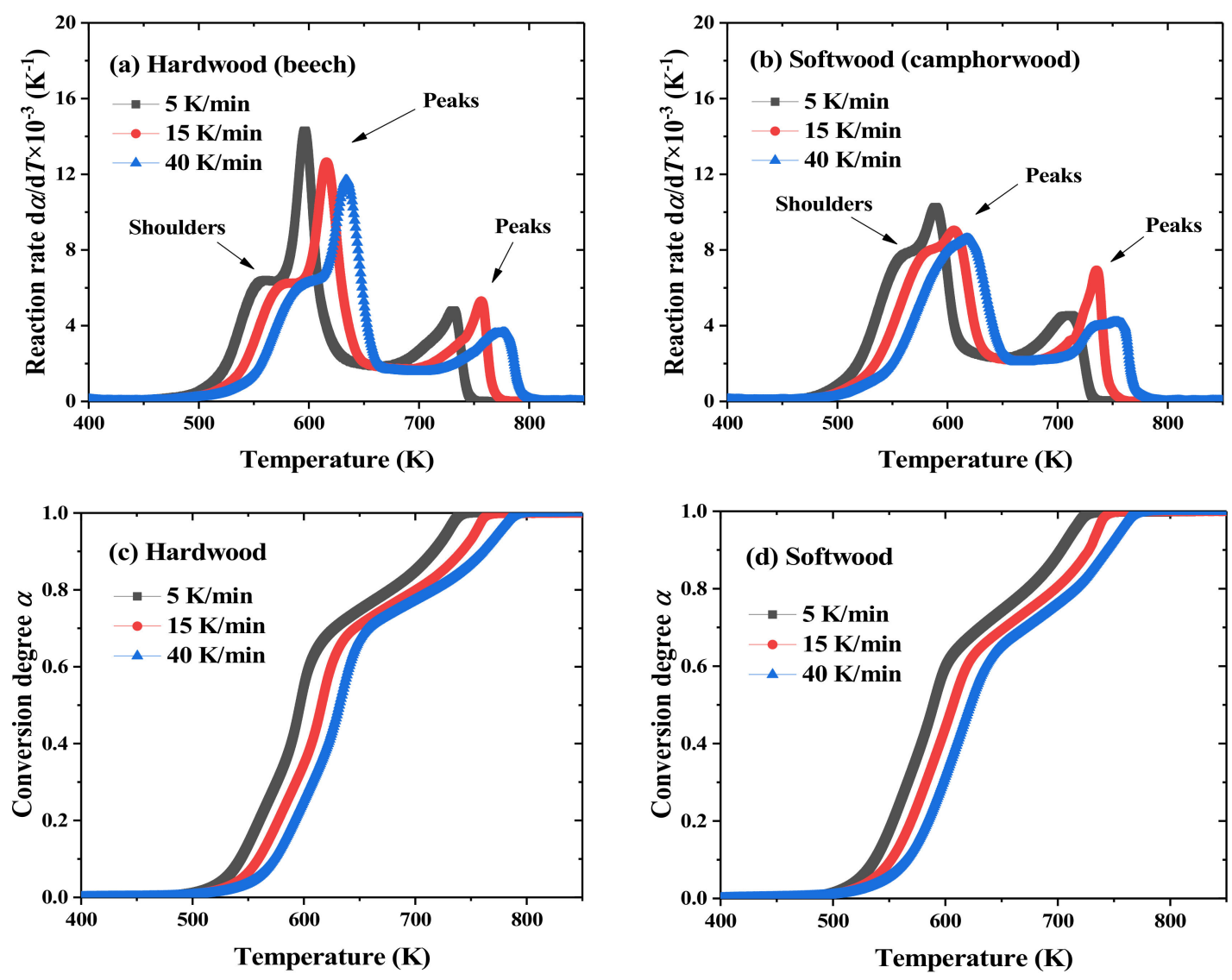

Figure 2. The $\mathrm{d} \alpha / \mathrm{d} T$ and $\alpha$ curves of beech and camphorwood degradation at various heating rates.
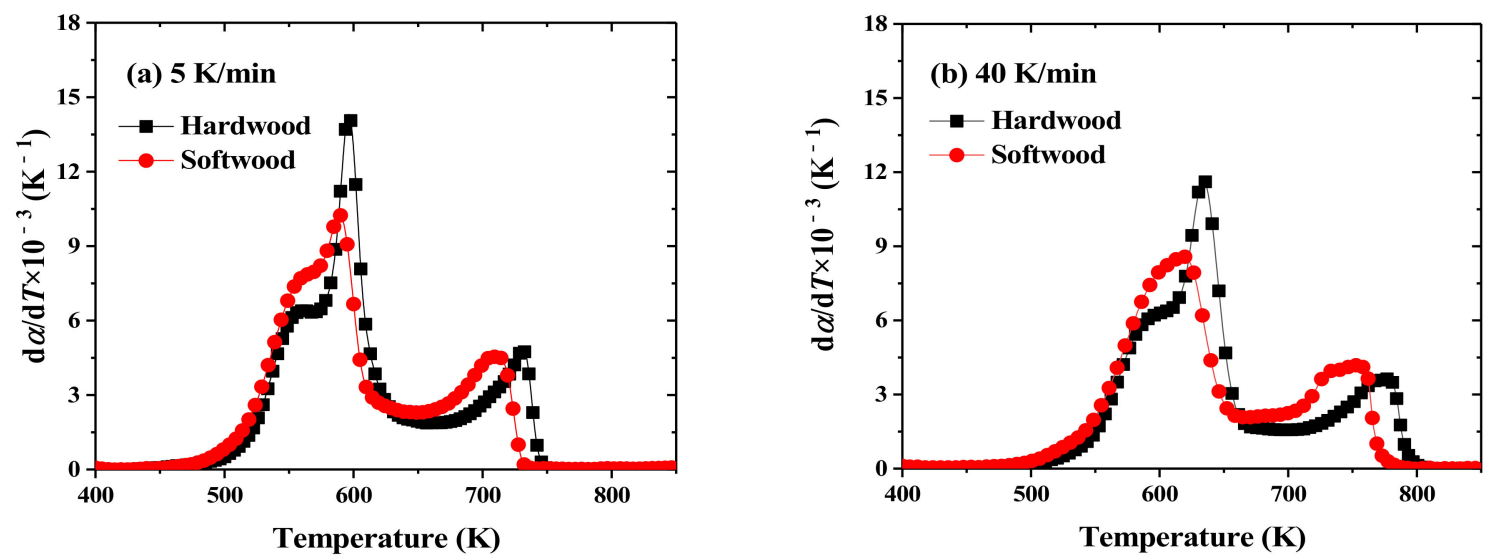

Figure 3. The $\mathrm{d} \alpha / \mathrm{d} T$ curves of beech and camphorwood under 5 and $40 \mathrm{~K} / \mathrm{min}$. 
Table 2. The details of hardwood and softwood decomposition based upon $\alpha$ and $\mathrm{d} \alpha / \mathrm{d} T$.

\begin{tabular}{|c|c|c|c|c|c|}
\hline Sample & $\begin{array}{l}\text { Heating Rate } \\
\text { (K/min) }\end{array}$ & $\begin{array}{l}\text { Decomposition } \\
\text { Temperature } \\
\text { Range (K) }\end{array}$ & $\begin{array}{c}\text { Shoulder Temperature } \\
\text { (K)/Reaction Rate } \\
\left(\mathrm{K}^{-1}\right) / \text { Conversion } \\
\text { Degree } \alpha\end{array}$ & $\begin{array}{c}\text { First Peak Temperature } \\
\text { (K)/Reaction Rate } \\
\left(\mathrm{K}^{-1}\right) / \text { Conversion Degree } \alpha\end{array}$ & $\begin{array}{c}\text { Second Peak } \\
\text { Temperature } \\
(\mathrm{K}) / \text { Reaction Rate } \\
\left(\mathrm{K}^{-1}\right) / \text { Conversion } \\
\text { Degree } \alpha \\
\end{array}$ \\
\hline \multirow{3}{*}{ Hardwood } & 5 & $451-753$ & $560.82 / 6.41 \times 10^{-3} / 0.21$ & $596.27 / 14.30 \times 10^{-3} / 0.50$ & $730.93 / 4.80 \times 10^{-3} / 0.96$ \\
\hline & 15 & $459-781$ & $582.49 / 6.25 \times 10^{-3} / 0.23$ & $616.05 / 12.65 \times 10^{-3} / 0.50$ & $756.53 / 5.30 \times 10^{-3} / 0.96$ \\
\hline & 40 & $469-810$ & $596.61 / 6.23 \times 10^{-3} / 0.23$ & $634.01 / 11.69 \times 10^{-3} / 0.52$ & $776.22 / 3.63 \times 10^{-3} / 0.96$ \\
\hline \multirow{3}{*}{ Softwood } & 5 & $441-738$ & $564.67 / 7.88 \times 10^{-3} / 0.29$ & $589.10 / 10.26 \times 10^{-3} / 0.50$ & $711.54 / 4.55 \times 10^{-3} / 0.94$ \\
\hline & 15 & $444-765$ & $585.76 / 8.03 \times 10^{-3} / 0.32$ & $606.09 / 9.04 \times 10^{-3} / 0.49$ & $735.42 / 6.93 \times 10^{-3} / 0.95$ \\
\hline & 40 & $448-795$ & $606.66 / 8.25 \times 10^{-3} / 0.37$ & $618.12 / 8.59 \times 10^{-3} / 0.47$ & $752.70 / 4.18 \times 10^{-3} / 0.94$ \\
\hline
\end{tabular}

\subsection{Kinetic and Thermodynamic Analysis}

\subsubsection{Activation Energy by KAS Approach}

Activation energy represents the minimum energy required to initiate a reaction. The activation energy has little change with the conversion degree in one certain thermal degradation stage, indicating that the degradation stage is controlled by a one-step reaction [45]. In addition, the activation energy has a significant effect on the reaction rate.

Based upon the KAS approach, with the conversion degree, $\alpha$, chosen from 0.1 to 0.9 , the plots of $\ln \left(\beta / T^{2}\right)$ versus 1/T are depicted in Figure $4 \mathrm{a}, \mathrm{b}$ for hardwood and softwood, respectively. Then, the values of activation energy were computed by the slopes $\left(-E_{\alpha} / \mathrm{R}\right)$ of the linear regression equation at different conversion degrees, as illustrated in Table 3 and Figure 5.
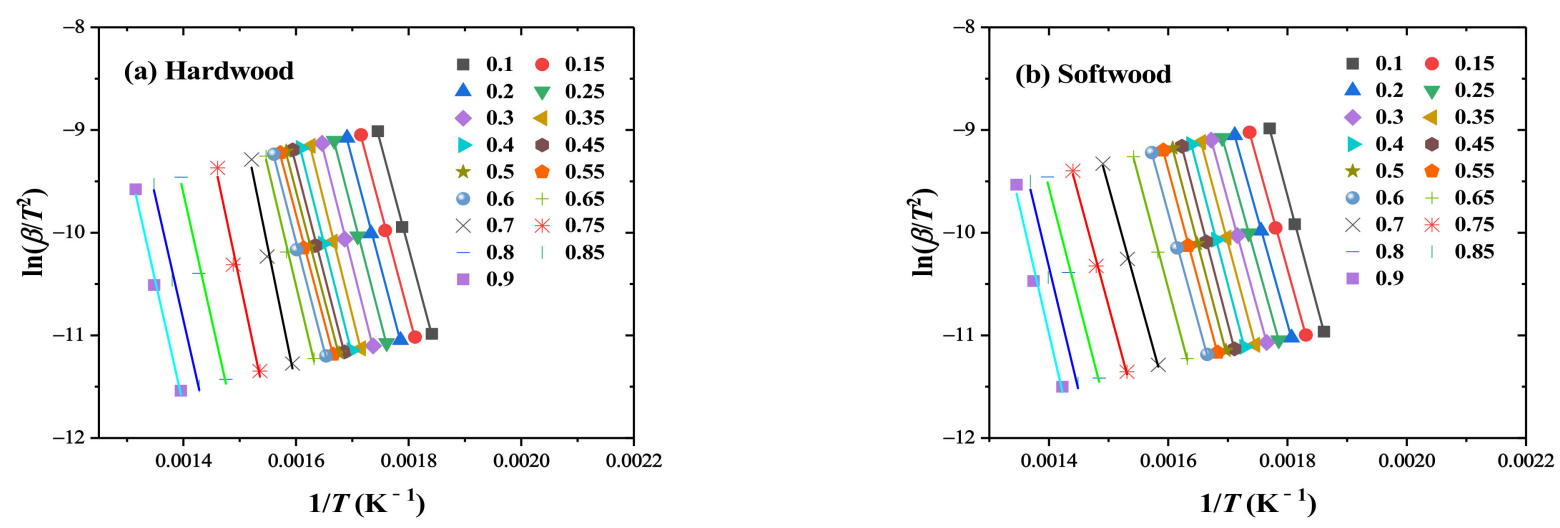

Figure 4. The plots of the KAS method at different conversion degrees for (a) hardwood and (b) softwood.

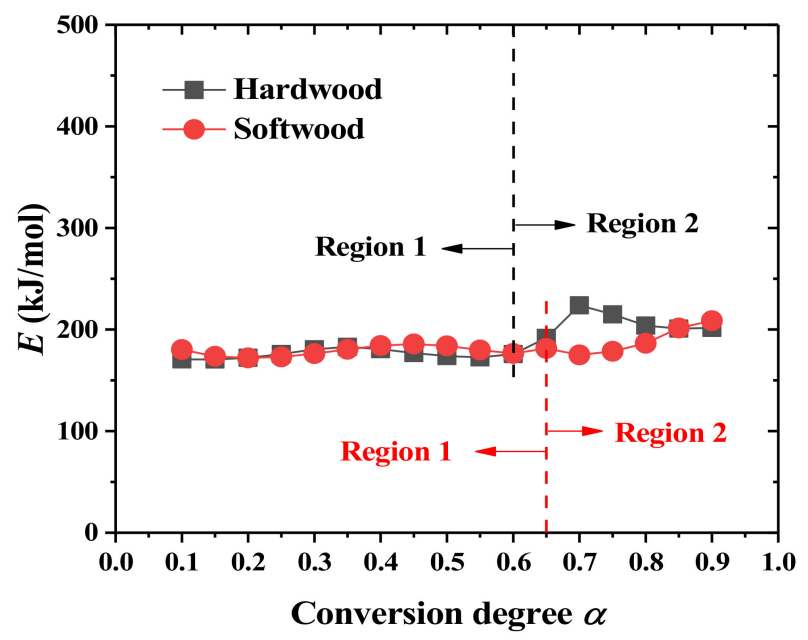

Figure 5. The activation energy as a function of conversion degree for hardwood and softwood. 
Table 3. $E, A$, and $R^{2}$ values for hardwood and softwood based upon the KAS method.

\begin{tabular}{|c|c|c|c|c|c|c|c|c|}
\hline \multirow{2}{*}{$\alpha$} & \multicolumn{3}{|c|}{ Hardwood } & \multicolumn{3}{|c|}{ Softwood } & \multirow{2}{*}{$\begin{array}{c}\text { Standard } \\
\text { Deviation of } \\
E \text { Values }\end{array}$} & \multirow{2}{*}{$\begin{array}{c}\text { Standard } \\
\text { Deviation of } \\
A \text { Values }\end{array}$} \\
\hline & $E(\mathrm{~kJ} / \mathrm{mol})$ & $R^{2}$ & $A\left(\min ^{-1}\right)$ & $E(\mathrm{~kJ} / \mathrm{mol})$ & $R^{2}$ & $A\left(\min ^{-1}\right)$ & & \\
\hline 0.10 & 170.62 & 0.9985 & 29.99 & 180.31 & 0.9997 & 32.72 & 4.85 & 1.37 \\
\hline 0.15 & 170.42 & 0.9984 & 30.14 & 173.60 & 0.9997 & 31.40 & 1.59 & 0.63 \\
\hline 0.20 & 172.22 & 0.9982 & 30.60 & 172.01 & 0.9998 & 31.17 & 0.11 & 0.29 \\
\hline 0.25 & 175.89 & 0.9981 & 31.34 & 173.03 & 0.9999 & 31.46 & 1.43 & 0.06 \\
\hline 0.30 & 180.56 & 0.9975 & 32.21 & 176.30 & 1.0000 & 32.18 & 2.13 & 0.02 \\
\hline 0.35 & 182.94 & 0.9968 & 32.57 & 180.53 & 1.0000 & 33.06 & 1.21 & 0.25 \\
\hline 0.40 & 180.64 & 0.9961 & 32.02 & 184.21 & 1.0000 & 33.80 & 1.79 & 0.89 \\
\hline 0.45 & 176.89 & 0.9964 & 31.24 & 185.83 & 0.9998 & 34.10 & 4.47 & 1.43 \\
\hline 0.50 & 173.87 & 0.9967 & 30.66 & 183.91 & 0.9993 & 33.68 & 5.02 & 1.51 \\
\hline 0.55 & 172.59 & 0.9969 & 30.42 & 179.80 & 0.9993 & 32.82 & 3.61 & 1.20 \\
\hline 0.60 & 175.92 & 0.9962 & 31.06 & 176.45 & 0.9993 & 32.05 & 0.27 & 0.50 \\
\hline 0.65 & 191.68 & 0.9940 & - & 181.35 & 0.9986 & 32.61 & 5.17 & - \\
\hline 0.70 & 223.85 & 0.9753 & - & 175.02 & 0.9974 & - & 24.42 & - \\
\hline 0.75 & 214.93 & 0.9706 & - & 178.48 & 0.9948 & - & 18.23 & - \\
\hline 0.80 & 203.91 & 0.9815 & - & 186.50 & 0.9875 & - & 8.71 & - \\
\hline 0.85 & 200.89 & 0.9858 & - & 201.42 & 0.9725 & - & 0.27 & - \\
\hline 0.90 & 201.56 & 0.9888 & - & 208.64 & 0.9700 & - & 3.54 & - \\
\hline Average 1 & 175.69 & 0.9973 & 31.11 & 178.73 & 0.9997 & 32.59 & 1.52 & - \\
\hline Average 2 & 206.14 & 0.9827 & - & 188.57 & 0.9868 & - & 8.79 & 0.74 \\
\hline Average & 186.43 & 0.9921 & - & 182.20 & 0.9952 & - & 2.12 & - \\
\hline
\end{tabular}

For hardwood, the $E$ value remained at about $175 \mathrm{~kJ} / \mathrm{mol}$ from $\alpha=0.1$ to $\alpha=0.6$, and then it varied largely in the range of $0.6-0.9$. The process of hardwood degradation can be divided into regions 1 and 2 by the inflection point of 0.6 conversion degree. The average $E$ estimates were 175.69 and $206.14 \mathrm{~kJ} / \mathrm{mol}$ for regions 1 and 2, respectively. For softwood, the $E$ value remained at about $178 \mathrm{~kJ} / \mathrm{mol}$ from $\alpha=0.1$ to $\alpha=0.65$, and then it rose from 181.35 to $208.64 \mathrm{~kJ} / \mathrm{mol}$ in the range of $0.65-0.9$. Similarly, the process of softwood decomposition can be divided into region $1(0 \leq \alpha \leq 0.65)$ and region $2(0.65<\alpha \leq 1)$. The mean $E$ estimates were 178.73 and $188.57 \mathrm{~kJ} / \mathrm{mol}$ for regions 1 and 2, respectively. To sum up, the thermal degradation occurring in region 1 for both hardwood and softwood is controlled by a one-step reaction. It is noted that the valuable products were mainly released in the decomposition reaction of region 1 . Besides, the mean $E$ value of hardwood was greater than that of softwood in the whole decomposition process. It is indicated that the occurrence of the thermal degradation of softwood was easier than hardwood.

\subsubsection{Kinetic Mechanisms by the CR Approach}

As demonstrated in Section 3.2.1, the average $E$ values in region 1 estimated by the KAS method were 175.69 and $178.73 \mathrm{~kJ} / \mathrm{mol}$ for beech and camphorwood, respectively. However, the kinetic model $g(\alpha)$ and $A$ values in region 1 have not been revealed. The CR approach was employed to determine $g(\alpha)$ and $A$ values in this section. The above three kinetic parameters will be used for kinetic modeling in the next section.

The activation energy, pre-exponential factor, and corresponding correlation coefficient, $R^{2}$, values of region 1 estimated via the CR approach with multiple kinetic models for hardwood and softwood are demonstrated in Tables 4 and 5, respectively. If the average $E$ value of region 1 estimated using the $C R$ approach with a given kinetic model is near the mean $E$ value acquired via the KAS approach, the decomposition reaction occurring in region 1 is controlled by the given kinetic model. 
Table 4. $E, \ln A$, and $R^{2}$ values of hardwood computed via the $C R$ approach with 18 kinetic models at different heating rates in region 1.

\begin{tabular}{|c|c|c|c|c|c|c|c|c|c|c|c|c|c|}
\hline \multirow[b]{2}{*}{ No. } & \multirow[b]{2}{*}{$g(\alpha)$} & \multicolumn{3}{|c|}{$5 \mathrm{~K} / \mathrm{min}$} & \multicolumn{3}{|c|}{$15 \mathrm{~K} / \mathrm{min}$} & \multicolumn{3}{|c|}{$40 \mathrm{~K} / \mathrm{min}$} & \multicolumn{3}{|c|}{ Average Value } \\
\hline & & $\begin{array}{c}E \\
(\mathrm{~kJ} / \mathrm{mol})\end{array}$ & $\begin{array}{c}\ln A \\
\left(\min ^{-1}\right)\end{array}$ & $R^{2}$ & $\begin{array}{c}E \\
(\mathrm{~kJ} / \mathrm{mol})\end{array}$ & $\underset{\left(\min ^{-1}\right)}{\ln A}$ & $R^{2}$ & $E(\mathrm{~kJ} / \mathrm{mol})$ & $\begin{array}{c}\ln A \\
\left(\min ^{-1}\right)\end{array}$ & $R^{2}$ & $\begin{array}{c}E \\
(\mathrm{~kJ} / \mathrm{mol})\end{array}$ & $\underset{\left(\min ^{-1}\right)}{\ln A}$ & $R^{2}$ \\
\hline 1 & $\alpha^{3 / 2}$ & 111.54 & 19.78 & 0.9722 & 115.1 & 21.19 & 0.9769 & 116.54 & 21.56 & 0.9772 & 114.39 & 20.84 & 0.9754 \\
\hline 2 & $\alpha^{1 / 2}$ & 30.86 & 2.92 & 0.9586 & 31.88 & 4.3 & 0.9656 & 32.2 & 4.86 & 0.9658 & 31.65 & 4.03 & 0.9633 \\
\hline 3 & $\alpha^{1 / 3}$ & 17.41 & -0.25 & 0.9415 & 18.01 & 1.13 & 0.9512 & 18.15 & 1.72 & 0.9512 & 17.86 & 0.87 & 0.948 \\
\hline 4 & $\alpha^{1 / 4}$ & 10.69 & -2.03 & 0.9127 & 11.08 & -0.65 & 0.927 & 11.12 & -0.05 & 0.9262 & 10.96 & -0.91 & 0.922 \\
\hline 5 & $-\ln (1-\alpha)$ & 85.95 & 15.04 & 0.9884 & 87.18 & 16.1 & 0.9898 & 88.27 & 16.54 & 0.9907 & 87.13 & 15.89 & 0.9896 \\
\hline 6 & $(1-\alpha)^{-1}-1$ & 103.3 & 19.09 & 0.9936 & 102.98 & 19.7 & 0.9941 & 104.31 & 20.12 & 0.9956 & 103.53 & 19.64 & 0.9944 \\
\hline 7 & $(1-\alpha)^{-2}-1$ & 123.13 & 24.38 & 0.9887 & 120.82 & 24.43 & 0.9903 & 122.43 & 24.81 & 0.9923 & 122.13 & 24.54 & 0.9904 \\
\hline 8 & {$[-\ln (1-\alpha)]^{2 / 3}$} & 54.14 & 8.28 & 0.9869 & 54.88 & 9.44 & 0.9883 & 55.52 & 9.95 & 0.9893 & 54.85 & 9.22 & 0.9882 \\
\hline 9 & {$[-\ln (1-\alpha)]^{1 / 2}$} & 38.24 & 4.79 & 0.985 & 38.73 & 5.99 & 0.9866 & 39.15 & 6.54 & 0.9877 & 38.71 & 5.77 & 0.9864 \\
\hline 10 & {$[-\ln (1-\alpha)]^{1 / 3}$} & 22.33 & 1.1 & 0.9799 & 22.58 & 2.35 & 0.982 & 22.78 & 2.94 & 0.9833 & 22.56 & 2.13 & 0.9817 \\
\hline 11 & {$[-\ln (1-\alpha)]^{1 / 4}$} & 14.38 & -0.91 & 0.972 & 14.5 & 0.36 & 0.9748 & 14.59 & 0.96 & 0.9763 & 14.49 & 0.14 & 0.9744 \\
\hline 12 & {$[-\ln (1-\alpha)]^{2}$} & 170.83 & 32.45 & 0.9943 & 172.14 & 32.98 & 0.9953 & 175.97 & 33.55 & 0.9961 & 172.98 & 32.99 & 0.9952 \\
\hline 13 & {$[-\ln (1-\alpha)]^{3}$} & 276.82 & 53.96 & 0.9902 & 280.99 & 54.45 & 0.9913 & 284.74 & 54.46 & 0.9921 & 280.85 & 54.29 & 0.9912 \\
\hline 14 & {$[-\ln (1-\alpha)]^{4}$} & 372.26 & 73.14 & 0.9904 & 377.89 & 73.33 & 0.9915 & 382.98 & 73.13 & 0.9923 & 377.71 & 73.2 & 0.9914 \\
\hline 15 & $1-(1-\alpha)^{1 / 2}$ & 78.25 & 12.53 & 0.9808 & 80.07 & 13.77 & 0.9837 & 81.05 & 14.22 & 0.9843 & 79.79 & 13.51 & 0.9829 \\
\hline 16 & $1-(1-\alpha)^{1 / 3}$ & 80.75 & 12.71 & 0.9838 & 82.38 & 13.9 & 0.986 & 83.4 & 14.35 & 0.9867 & 82.18 & 13.65 & 0.9855 \\
\hline 17 & $\alpha^{2}$ & 151.88 & 27.88 & 0.9735 & 156.7 & 29.29 & 0.978 & 158.71 & 29.58 & 0.9783 & 155.76 & 28.92 & 0.9766 \\
\hline 18 & $\alpha+(1-\alpha) \ln (1-\alpha)$ & 160.89 & 29.26 & 0.9801 & 165.16 & 30.5 & 0.9832 & 167.29 & 30.77 & 0.9837 & 164.45 & 30.18 & 0.9823 \\
\hline 19 & $1-2 / 3 \alpha-(1-\alpha)^{2 / 3}$ & 164.24 & 28.53 & 0.9822 & 168.26 & 29.7 & 0.9849 & 170.44 & 29.95 & 0.9854 & 167.65 & 29.39 & 0.9842 \\
\hline 20 & {$\left[(1-\alpha)^{-1 / 3}-1\right]^{2}$} & 192.38 & 34.98 & 0.9925 & 194.15 & 35.48 & 0.9932 & 196.72 & 35.69 & 0.9942 & 194.42 & 35.38 & 0.9933 \\
\hline
\end{tabular}

Table 5. $E, \ln A$, and $R^{2}$ values of softwood computed via the $C R$ approach with 18 kinetic models at different heating rates in region 1.

\begin{tabular}{|c|c|c|c|c|c|c|c|c|c|c|c|c|c|}
\hline \multirow[b]{2}{*}{ No. } & \multirow[b]{2}{*}{$g(\alpha)$} & \multicolumn{3}{|c|}{$5 \mathrm{~K} / \mathrm{min}$} & \multicolumn{3}{|c|}{$15 \mathrm{~K} / \mathrm{min}$} & \multicolumn{3}{|c|}{$40 \mathrm{~K} / \mathrm{min}$} & \multicolumn{3}{|c|}{ Average value } \\
\hline & & $\begin{array}{c}E \\
(\mathrm{~kJ} / \mathrm{mol})\end{array}$ & $\begin{array}{c}\ln A \\
\left(\min ^{-1}\right)\end{array}$ & $R^{2}$ & $\begin{array}{c}E \\
(\mathrm{~kJ} / \mathrm{mol})\end{array}$ & $\begin{array}{c}\ln A \\
\left(\min ^{-1}\right)\end{array}$ & $R^{2}$ & $E(\mathrm{~kJ} / \mathrm{mol})$ & $\underset{\left(\min ^{-1}\right)}{\ln A}$ & $R^{2}$ & $\begin{array}{c}E \\
(\mathrm{~kJ} / \mathrm{mol})\end{array}$ & $\begin{array}{c}\ln A \\
\left(\min ^{-1}\right)\end{array}$ & $R^{2}$ \\
\hline 1 & $\alpha^{3 / 2}$ & 105.58 & 18.77 & 0.9478 & 104.48 & 18.95 & 0.9514 & 104.42 & 19.35 & 0.9589 & 104.83 & 19.02 & 0.9527 \\
\hline 2 & $\alpha^{1 / 2}$ & 28.92 & 2.55 & 0.9218 & 28.38 & 3.29 & 0.9256 & 28.21 & 4.04 & 0.9357 & 28.5 & 3.29 & 0.9277 \\
\hline 3 & $\alpha^{1 / 3}$ & 16.15 & -0.52 & 0.8892 & 15.7 & 0.3 & 0.8922 & 15.51 & 1.11 & 0.905 & 15.79 & 0.3 & 0.8955 \\
\hline 4 & $\alpha^{1 / 4}$ & 9.76 & -2.27 & 0.8345 & 9.35 & -1.41 & 0.8343 & 9.15 & -0.59 & 0.8499 & 9.42 & -1.42 & 0.8396 \\
\hline 5 & $-\ln (1-\alpha)$ & 81.7 & 14.33 & 0.9747 & 80.71 & 14.67 & 0.9771 & 80.5 & 15.15 & 0.9818 & 80.97 & 14.72 & 0.9779 \\
\hline 6 & $(1-\alpha)^{-1}-1$ & 98.75 & 18.37 & 0.9923 & 97.57 & 18.58 & 0.9935 & 97.24 & 18.94 & 0.9952 & 97.85 & 18.63 & 0.9937 \\
\hline 7 & $(1-\alpha)^{-2}-1$ & 118.3 & 23.65 & 0.998 & 116.91 & 23.69 & 0.9982 & 116.43 & 23.94 & 0.9973 & 117.21 & 23.76 & 0.9978 \\
\hline 8 & {$[-\ln (1-\alpha)]^{2 / 3}$} & 51.33 & 7.8 & 0.9711 & 50.58 & 8.37 & 0.9737 & 50.37 & 8.99 & 0.9789 & 50.76 & 8.39 & 0.9746 \\
\hline 9 & {$[-\ln (1-\alpha)]^{1 / 2}$} & 36.15 & 4.41 & 0.9668 & 35.52 & 5.09 & 0.9695 & 35.3 & 5.8 & 0.9754 & 35.66 & 5.1 & 0.9706 \\
\hline 10 & {$[-\ln (1-\alpha)]^{1 / 3}$} & 20.96 & 0.83 & 0.9551 & 20.46 & 1.62 & 0.958 & 20.23 & 2.39 & 0.9655 & 20.55 & 1.61 & 0.9595 \\
\hline 11 & {$[-\ln (1-\alpha)]^{1 / 4}$} & 13.37 & -1.14 & 0.937 & 12.93 & -0.3 & 0.9396 & 12.7 & 0.51 & 0.9494 & 13 & -0.31 & 0.942 \\
\hline 12 & {$[-\ln (1-\alpha)]^{2}$} & 160.56 & 30.68 & 0.9801 & 160.72 & 30.8 & 0.9781 & 162.88 & 31.35 & 0.9796 & 161.39 & 30.95 & 0.9793 \\
\hline 13 & {$[-\ln (1-\alpha)]^{3}$} & 263.91 & 51.91 & 0.9786 & 261.48 & 50.88 & 0.9808 & 261.3 & 50.46 & 0.9849 & 262.23 & 51.09 & 0.9814 \\
\hline 14 & {$[-\ln (1-\alpha)]^{4}$} & 355.02 & 70.41 & 0.979 & 351.86 & 68.7 & 0.9812 & 351.7 & 67.82 & 0.9852 & 352.86 & 68.98 & 0.9818 \\
\hline 15 & $1-(1-\alpha)^{1 / 2}$ & 74.15 & 11.83 & 0.9605 & 73.25 & 12.24 & 0.9636 & 73.09 & 12.76 & 0.9699 & 73.5 & 12.28 & 0.9647 \\
\hline 16 & $1-(1-\alpha)^{1 / 3}$ & 76.59 & 12.01 & 0.9657 & 75.67 & 12.4 & 0.9685 & 75.49 & 12.91 & 0.9743 & 75.92 & 12.44 & 0.9695 \\
\hline 17 & $\alpha^{2}$ & 143.91 & 26.55 & 0.9502 & 142.53 & 26.45 & 0.9538 & 142.53 & 26.66 & 0.9609 & 142.99 & $\begin{array}{l}12.44 \\
26.55\end{array}$ & 0.955 \\
\hline 18 & $\alpha+(1-\alpha) \ln (1-\alpha)$ & 152.72 & 27.91 & 0.9602 & 151.23 & 27.74 & 0.9634 & 151.17 & 27.9 & 0.9696 & 151.71 & 27.85 & 0.9644 \\
\hline 19 & $1-2 / 3 \alpha-(1-\alpha)^{2 / 3}$ & 156 & 27.18 & 0.9637 & 154.48 & 26.97 & 0.9667 & 154.4 & 27.11 & 0.9726 & 154.96 & 27.09 & 0.9677 \\
\hline 20 & {$\left[(1-\alpha)^{-1 / 3}-1\right]^{2}$} & 183.6 & 33.59 & 0.9841 & 181.77 & 33.16 & 0.986 & 181.5 & 33.12 & 0.9893 & $\begin{array}{l}134.90 \\
182.29\end{array}$ & 33.29 & 0.9865 \\
\hline
\end{tabular}

For hardwood, there is a big difference between the average $E$ value attained by the CR approach with the power law, reaction order, contracting, and diffusion models, and that acquired by the KAS method in region 1. However, for the Avrami-Erofeev model, $g(\alpha)$ $=[-\ln (1-\alpha)]^{2}$, the mean $E$ value $(172.98 \mathrm{~kJ} / \mathrm{mol})$ is closest to the value $(175.69 \mathrm{~kJ} / \mathrm{mol})$ calculated via the KAS approach, and the corresponding correlation coefficient, $R^{2}$, is much higher. Thus, the Avrami-Erofeev model, $g(\alpha)=[-\ln (1-\alpha)]^{2}$, is in charge of the thermal decomposition of hardwood in region 1 . For softwood, the mean $E$ value $(178.73 \mathrm{~kJ} / \mathrm{mol})$ estimated using the 3D diffusional model, $g(\alpha)=\left[(1-\alpha)^{-1 / 3}-1\right]^{2}$, is near the calculated value $(182.29 \mathrm{~kJ} / \mathrm{mol})$ of the KAS approach. The corresponding correlation coefficient, $R^{2}$, exceeds 0.98 . The most closely matched model for characterizing the degradation process of softwood in region 1 is the 3D diffusion model. Moreover, the pre-exponential factor $A$ of hardwood and softwood in region 1 is obtained based upon the acquired kinetic models, as shown in Table 3. The pre-exponential factor represents the collision frequency between molecules in a reactive system, and the $A$ value higher than $10^{9} \mathrm{~s}^{-1}\left(\ln A=24.82 \mathrm{~min}^{-1}\right)$ 
means that the reactive system has high reactivity. The $A$ values of hardwood and softwood in region 1 are all greater than $24.82 \mathrm{~min}^{-1}$. The average $\ln A$ value of hardwood is smaller than that of softwood in region 1.

As shown in Equation (11), the kinetic compensation effect (KCE) [46] is a linear relationship between $E$ and $\ln A$ at various heating rates. $E$ and $\ln A$ show a strong $\operatorname{linear}$ relationship, suggesting that the $E$ and $\ln A$ estimates computed using the CR approach with 18 kinetic models are reasonable and convincing.

$$
\ln A=a+b E
$$

where $a$ is a constant expressed as $a=\ln \left(k_{\text {iso }}\right) a=\ln \left(k_{i s o}\right) . b$ is also a constant expressed as $b=1 /\left(R T_{\text {iso }}\right) b=1 /\left(R T_{\text {iso }}\right) \cdot k_{\text {iso }}$ denotes the isokinetic rate constant and $T_{\text {iso }}$ represents the isokinetic temperature.

Figure $6 \mathrm{a}, \mathrm{b}$ illustrate the kinetic compensation effect for hardwood and softwood in region 1 at multiple heating rates, respectively. The detailed information about "KCE" parameters is listed in Table 6 . If the $T_{\text {iso }}$ value is covered by the temperature range of region 1, then a strong linear relationship between $E$ and $\ln A$ will occur in region 1 [45]. As shown in Table 6, the $T_{\text {iso }}$ values are among the temperature range of region 1 under three heating rates for both hardwood and softwood. All the corresponding $R^{2}$ values are much higher. As a consequence, the $E$ and $\ln A$ estimates acquired by the CR approach for hardwood and softwood are reasonable and convincing.
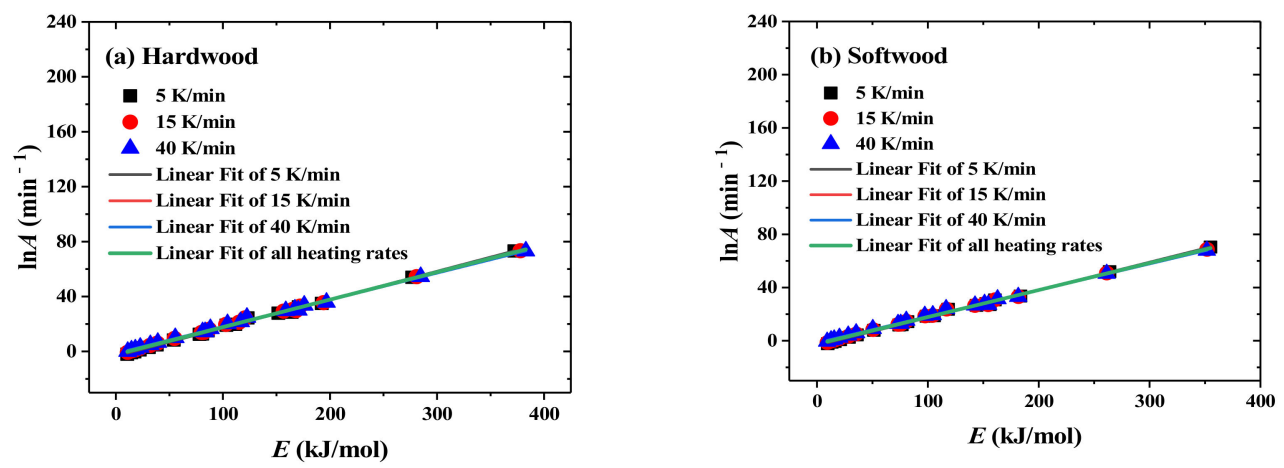

Figure 6. The kinetic compensation effect of region 1 for (a) hardwood and (b) softwood.

Table 6. KCE parameters and corresponding $R^{2}$.

\begin{tabular}{|c|c|c|c|c|c|c|c|c|c|}
\hline Sample & $\beta(\mathrm{K} / \mathrm{min})$ & $a\left(\mathrm{~s}^{-1}\right)$ & $95 \%$ CI of $a$ & $b(\mathrm{~mol} / \mathrm{kJ})$ & $95 \%$ CI of $b$ & $k_{i s o}$ & $T_{i s o}(\mathrm{~K})$ & $R^{2}$ & $\begin{array}{l}\text { Temperature Range of } \\
\text { Region } 1(\mathrm{~K})\end{array}$ \\
\hline \multirow{3}{*}{ Hardwood } & 5 & -3.3864 & $\begin{array}{l}(-3.7181 \\
-3.0547)\end{array}$ & 0.2059 & $\begin{array}{l}(0.2036, \\
0.2082)\end{array}$ & 0.0338 & 584.16 & 0.9977 & $400-605$ \\
\hline & 15 & -2.0282 & $\begin{array}{l}(-2.3536 \\
-1.7028)\end{array}$ & 0.1997 & $\begin{array}{l}(0.1975, \\
0.2019)\end{array}$ & 0.1316 & 602.30 & 0.9977 & $400-624$ \\
\hline & 40 & -1.3764 & $\begin{array}{l}(-1.7022, \\
-1.0506)\end{array}$ & 0.1948 & $\begin{array}{l}(0.1926, \\
0.1970)\end{array}$ & 0.2525 & 617.45 & 0.9976 & $400-641$ \\
\hline \multirow{5}{*}{ Softwood } & Total heating rates & -2.2630 & $\begin{array}{l}(-2.4769, \\
-2.0491)\end{array}$ & 0.2001 & $\begin{array}{l}(0.1986, \\
0.2015)\end{array}$ & 0.1040 & 601.09 & 0.9969 & - \\
\hline & 5 & -3.4308 & $\begin{array}{l}(-3.7637 \\
-3.0979)\end{array}$ & 0.2084 & $\begin{array}{l}(0.2060, \\
0.2108)\end{array}$ & 0.0324 & 577.15 & 0.9975 & $400-613$ \\
\hline & 15 & -2.4137 & $\begin{array}{l}(-2.7468 \\
-2.0805)\end{array}$ & 0.2025 & $\begin{array}{l}(0.2001, \\
0.2050)\end{array}$ & 0.0895 & 593.97 & 0.9973 & $400-632$ \\
\hline & 40 & -1.4932 & $\begin{array}{l}(-1.8264, \\
-1.1599)\end{array}$ & 0.1975 & $\begin{array}{l}(0.2000, \\
0.1951)\end{array}$ & 0.2247 & 609.01 & 0.9971 & $400-648$ \\
\hline & Total heating rates & -2.4441 & $\begin{array}{l}(-2.6568, \\
-2.2314)\end{array}$ & 0.2028 & $\begin{array}{l}(0.2013, \\
0.2044)\end{array}$ & 0.0868 & 593.09 & 0.9966 & - \\
\hline
\end{tabular}

\subsubsection{Thermodynamic Analyses}

The values of the changes in enthalpy $(\Delta H)$, Gibbs free energy $(\Delta G)$, and entropy $(\Delta S)$ of hardwood and softwood in region 1 were estimated from the thermogravimetric data at the heating rate of $15 \mathrm{~K} / \mathrm{min}$, as listed in Table 7 . The difference between $E$ and $\Delta H$ 
represents the potential energy barrier in the process of biomass combustion [44]. The smaller the potential energy barrier, the easier the reactants transform into products. At the same conversion degree, the difference between $E$ and $\Delta H$ of hardwood is greater than that of softwood. This implies that the combustion reaction of softwood occurs easier than that of hardwood. The $\Delta S$ values of hardwood and softwood are all positive, implying that their combustion processes raise the disorder degree of the reactive system.

Table 7. $H, \Delta G$, and $\Delta S$ values of hardwood and softwood at $15 \mathrm{~K} / \mathrm{min}$.

\begin{tabular}{|c|c|c|c|c|c|c|}
\hline \multirow{2}{*}{$\begin{array}{l}\text { Conversion } \\
\text { Degree, } \alpha\end{array}$} & \multicolumn{3}{|c|}{ Hardwood } & \multicolumn{3}{|c|}{ Softwood } \\
\hline & $\Delta H(\mathrm{~kJ} / \mathrm{mol})$ & $\Delta G(\mathrm{~kJ} / \mathrm{mol})$ & $\Delta S(\mathrm{~J} /(\mathrm{mol} \cdot \mathrm{K}))$ & $\Delta H(\mathrm{~kJ} / \mathrm{mol})$ & $\Delta G(\mathrm{~kJ} / \mathrm{mol})$ & $\Delta S(\mathrm{~J} /(\mathrm{mol} \cdot \mathrm{K}))$ \\
\hline 0.1 & 165.97 & 171.63 & 16.73 & 175.72 & 152.63 & 38.10 \\
\hline 0.15 & 165.69 & 170.63 & 16.26 & 168.93 & 152.82 & 26.59 \\
\hline 0.2 & 167.43 & 170.11 & 19.17 & 167.27 & 152.86 & 23.78 \\
\hline 0.25 & 171.03 & 169.96 & 25.19 & 168.24 & 152.83 & 25.41 \\
\hline 0.3 & 175.63 & 170.17 & 32.88 & 171.45 & 152.74 & 30.88 \\
\hline 0.35 & 177.94 & 170.69 & 36.74 & 175.63 & 152.62 & 37.96 \\
\hline 0.4 & 175.59 & 171.23 & 32.82 & 179.26 & 152.52 & 44.12 \\
\hline 0.45 & 171.81 & 171.47 & 26.50 & 180.84 & 152.47 & 46.79 \\
\hline 0.5 & 168.75 & 171.44 & 21.39 & 178.87 & 152.53 & 43.46 \\
\hline 0.55 & 167.43 & 171.36 & 19.20 & 174.71 & 152.64 & 36.42 \\
\hline 0.6 & 170.73 & 171.44 & 24.71 & 171.30 & 152.73 & 30.63 \\
\hline 0.65 & - & - & - & 176.09 & 152.60 & 38.77 \\
\hline Average value & 170.73 & 170.92 & 24.69 & 174.03 & 152.67 & 35.24 \\
\hline
\end{tabular}

$\Delta G$ denotes the incremental energy of the reactive system and the direction of the combustion reaction. The $\Delta G$ value of hardwood is larger than that of softwood, which shows that the hardwood combustion is more difficult to be carried out than softwood combustion. The $\Delta G$ values of hardwood (beech wood) and softwood (camphorwood) are similar to other biomass raw materials, such as waste tea [47], cattle manure [48], and Lentinus edodes [49], which proves that beech wood and camphorwood can be appropriate biomass raw materials for bioenergy production.

\subsection{Kinetic Modeling}

Based upon the estimated kinetic triplet ( $E, A$, and kinetic model), the kinetic modeling for the thermal degradation process of hardwood and softwood in region 1 is conducted in this section. The mathematical expression of the conversion degree, $\alpha$, for hardwood and softwood can be derived from the obtained kinetic model combined with Equation (5), as presented in Equations (12) and (13):

$$
\begin{aligned}
& \alpha=1-\operatorname{EXP}\left[-\left(\frac{v(y-2) e^{-y}}{y^{3}}\right)^{\frac{1}{2}}\right] \\
& \alpha=1-\left[1+\left(\frac{v(y-2) e^{-y}}{y^{3}}\right)^{\frac{1}{2}}\right]^{-3}
\end{aligned}
$$

where $v=A E / \beta R$ and $y=E / R T$.

Figure $7 \mathrm{a}, \mathrm{b}$ show the experimental and simulated conversion degree curves under $5,15,20$, and $40 \mathrm{~K} / \mathrm{min}$ for beech and camphorwood, respectively. The simulated result is extremely consistent with the experimental results for hardwood and softwood at four different heating rates, and the correlation coefficients are greater than or equal to 0.9988 for both hardwood and softwood. Consequently, the estimated kinetic triplet can perfectly simulate the thermal degradation process of hardwood and softwood in region 1 at 5 , 15,20 , and $40 \mathrm{~K} / \mathrm{min}$. It is noted that the kinetic triplet used for modeling the thermal 
degradation process was obtained on the basis of the thermogravimetric experimental profile at 5,15 , and $40 \mathrm{~K} / \mathrm{min}$. However, the experimental profile under $20 \mathrm{~K} / \mathrm{min}$ was not used for calculating the kinetic triplet.
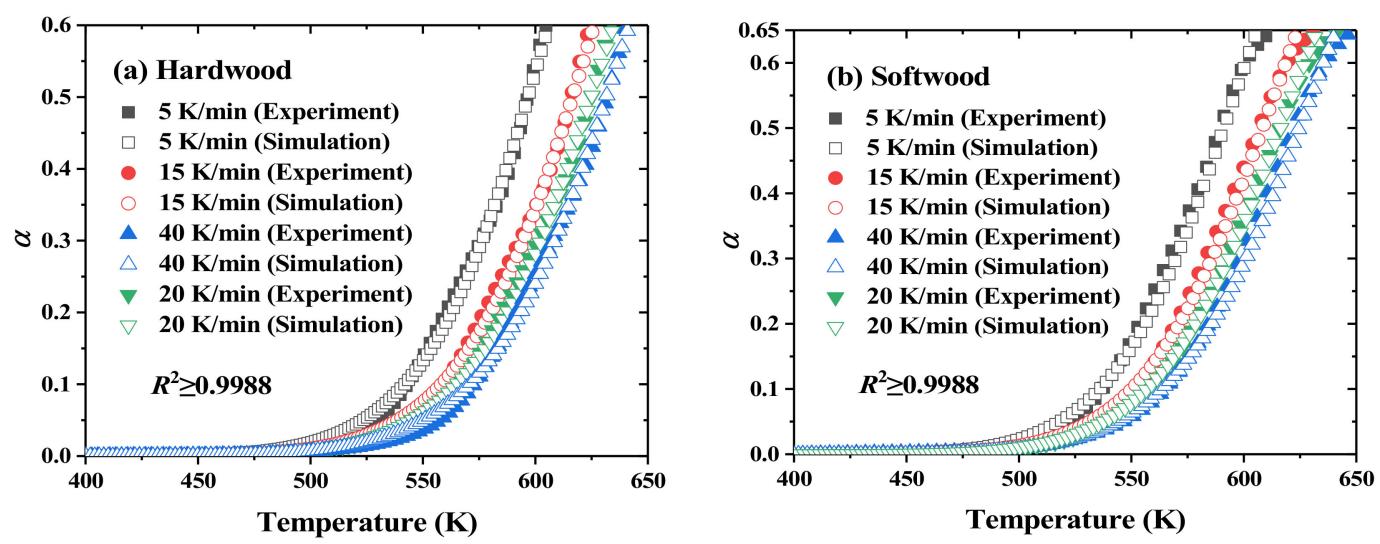

Figure 7. Comparison of the experiment with simulation at multiple heating rates.

\subsection{Combustion Characteristic Parameters' Analysis}

Based upon the method illustrated in Section 2.4, the characteristic temperature of hardwood and softwood combustion is obtained from TG and DTG curves, as presented in Table 8. As illustrated in Table 8, the $T_{\mathrm{i}}, T_{\mathrm{p}}$, and $T_{\mathrm{b}}$ values of hardwood and softwood exhibit an increasing trend with the increased heating rate, which means that heating rate has a delayed effect on biomass combustion. This can be explained by the thermal hysteresis effect. At the same heating rate, the ignition temperature, $T_{\mathrm{i}}$, of softwood is lower than that of hardwood, indicating that softwood is easier to ignite than hardwood. In addition, compared with softwood, the maximum combustion rate, $-R_{\mathrm{p}}$, of hardwood is higher, which implies that the burning reaction of hardwood is more intense.

Table 8. Combustion characteristic parameters of hardwood and softwood.

\begin{tabular}{|c|c|c|c|c|c|c|c|c|c|c|}
\hline \multirow[b]{2}{*}{ Biomass } & \multirow[b]{2}{*}{$\beta / \mathrm{K} \min ^{-1}$} & \multicolumn{3}{|c|}{ Temperature/K } & \multirow{2}{*}{$\begin{array}{l}-R_{\mathrm{p}} / \% \\
\min ^{-1}\end{array}$} & \multicolumn{3}{|c|}{ Time/min } & \multicolumn{2}{|c|}{ Combustion Parameters } \\
\hline & & $T_{\mathrm{i}}$ & $T_{\mathrm{p}}$ & $T_{\mathrm{b}}$ & & $t_{\mathbf{i}}$ & $t_{\mathrm{p}}$ & $t_{\mathrm{b}}$ & $\begin{array}{c}C / 10^{-4 \%} \\
\min ^{-1} K^{-2}\end{array}$ & $\begin{array}{c}C_{\mathrm{b}} / 10^{-4} \\
\min ^{-1}\end{array}$ \\
\hline \multirow{3}{*}{ Hardwood } & 5 & 561.19 & 596.44 & 748.24 & 6.60 & 47.61 & 54.66 & 85.02 & 0.21 & 18.19 \\
\hline & 15 & 578.20 & 616.05 & 770.28 & 17.51 & 17.00 & 19.56 & 29.81 & 0.52 & 52.22 \\
\hline & 40 & 589.01 & 634.01 & 800.23 & 42.13 & 6.65 & 7.77 & 11.93 & 1.21 & 117.80 \\
\hline \multirow{3}{*}{ Softwood } & 5 & 541.56 & 590.13 & 733.28 & 4.79 & 43.68 & 53.40 & 82.03 & 0.16 & 12.22 \\
\hline & 15 & 553.18 & 606.63 & 758.98 & 12.38 & 15.34 & 18.90 & 29.06 & 0.40 & 30.07 \\
\hline & 40 & 563.29 & 616.58 & 787.57 & 32.17 & 6.00 & 7.34 & 11.61 & 1.01 & 70.23 \\
\hline
\end{tabular}

To compare the combustion performance of hardwood and softwood, two combustion characteristic indexes are described, as [50]:

$$
\begin{aligned}
& C=\left(-R_{P}\right) / T_{i}^{2} \\
& C_{b}=\frac{\left(f_{1} \times f_{2}\right)}{t_{b}}
\end{aligned}
$$

where $f_{1}$ and $f_{2}$ correspond to the mass loss fraction before and after the ignition point. $f_{1}$ reflects the content ratio of volatiles, which relates with the effect of the ignition characteristic of biomass, while $f_{2}$ reflects the burnout character of biomass, which relates with the carbon contents and configuration of biomass. $C$ represents the reactivity of biomass at the ignition point, and $C_{b}$ describes the burnout characteristics and stability of biomass. The greater their value, the higher the combustion performance is. 
As illustrated in Table 8, with the increase of heating rate, the $C$ and $C_{b}$ values of hardwood and softwood apparently increase, which indicates that the heating rate has a significant promoting effect on combustion performance. The larger $C$ value of one certain biomass means that it has better thermal degradation stability after ignition. It is worth noting that the $C$ value of hardwood is higher than that of softwood at the same heating rate, implying that the thermal degradation stability of hardwood is higher than that of softwood. Moreover, the $C_{b}$ value of hardwood is higher than that of softwood at each heating rate, indicating that hardwood has better burnout characteristics. In conclusion, the combustion performance of hardwood is superior to softwood under the same external conditions (heating rate and atmosphere).

\section{Conclusions}

The main aim of this study was to provide guidance for utilizing woody biomass effectively for bioenergy and chemical feedstocks during the thermal degradation process. The thermal degradation characteristics and kinetic mechanisms of typical hardwood (beech wood) and softwood (camphorwood) were studied by employing a thermogravimetric analyzer at the heating rates of 5, 15, 20, and $40 \mathrm{~K} / \mathrm{min}$ under air. The KAS approach combined with the CR approach was applied to estimate the kinetic triplet.

(1) Softwood decomposition began and ended at lower temperatures than hardwood in air atmosphere. Two diverse peaks and one shoulder appeared on the reaction rate curves for both hardwood and softwood. The maximal reaction rate of hardwood was larger than that of softwood.

(2) The activation energy was maintained at a constant in the conversion degree range of 0.1-0.6 for hardwood, while $0.1-0.65$ for softwood. The thermal degradation process can be divided into two regions by the dividing points of $\alpha=0.6$ and $\alpha=0.65$ for hardwood and softwood, respectively. The mean $E$ value of hardwood was larger than that of softwood during the whole decomposition process.

(3) The thermal degradation process occurring in region 1 was dominated by the AvramiErofeev model $\left(g(\alpha)=[-\ln (1-\alpha)]^{2}\right)$ and the 3D diffusional model $\left(g(\alpha)=\left[(1-\alpha)^{-1 / 3}\right.\right.$ $-1]^{2}$ ) for hardwood and softwood, respectively. The average $A$ value of softwood was larger than that of hardwood in region 1.

(4) The simulated conversion degree curves were consistent with the experimental curves at 5, 15, 20, and $40 \mathrm{~K} / \mathrm{min}$. Therein, the thermogravimetric experimental profile under $20 \mathrm{~K} / \mathrm{min}$ was not used for estimating the kinetic triplet.

(5) The values of ignition temperature $\left(T_{\mathrm{i}}\right)$, peak temperature $\left(T_{\max }\right)$, and burnout temperature $\left(T_{b}\right)$ for both hardwood and softwood exhibited an increasing trend with the increased heating rate. Under the same external conditions (heating rate and atmosphere), the combustion performance of hardwood was superior to softwood.

Author Contributions: Conceptualization, X.X. and R.C.; investigation and experiment, X.X. and R.C.; writing—original draft X.X. and R.P.; writing-review and editing, X.X., R.C. and R.P. All authors have read and agreed to the published version of the manuscript.

Funding: This work was supported by the National Natural Science Foundation of China (No. 51806106), and the Science and Technology Department of Jiangsu Province, China (No: BK20170838).

Institutional Review Board Statement: Not applicable.

Informed Consent Statement: Not applicable.

Data Availability Statement: The data will be made available on request from the corresponding author.

Conflicts of Interest: The authors declare no conflict of interest. 


\section{References}

1. Zhang, W.; Zhang, J.; Ding, Y.; He, Q.; Lu, K.; Chen, H. Pyrolysis kinetics and reaction mechanism of expandable polystyrene by multiple kinetics methods. J. Clean. Prod. 2021, 285, 125042. [CrossRef]

2. Jia, G. Combustion Characteristics and Kinetic Analysis of Biomass Pellet Fuel Using Thermogravimetric Analysis. Processes 2021, 9, 868. [CrossRef]

3. Cao, W.; Li, W.; Yu, S.; Zhang, Y.; Shu, C.-M.; Liu, Y.; Luo, J.; Bu, L.; Tan, Y. Explosion venting hazards of temperature effects and pressure characteristics for premixed hydrogen-air mixtures in a spherical container. Fuel 2021, 290, 120034. [CrossRef]

4. Liu, W.; Yu, Z.; Zhu, Q.; Zhou, X.; Peng, C. Assessment of biomass utilization potential of Caragana korshinskii and its effect on carbon sequestration on the Northern Shaanxi Loess Plateau, China. Land Degrad. Dev. 2020, 31, 53-64. [CrossRef]

5. Mitchell, J. The "Greenhouse" effect and climate change. Rev. Geophys. 1989, 27, 115-139. [CrossRef]

6. Altantzis, A.-I.; Kallistridis, N.-C.; Stavropoulos, G.; Zabaniotou, A. Apparent Pyrolysis Kinetics and Index-Based Assessment of Pretreated Peach Seeds. Processes 2021, 9, 905. [CrossRef]

7. Wang, Z.; Wang, J.; Xie, L.; Zhu, H.; Shu, X. Influence of the Addition of Cotton Stalk during Co-pyrolysis with Sewage Sludge on the Properties, Surface Characteristics, and Ecological Risks of Biochars. J. Therm. Sci. 2019, 28, 755-762. [CrossRef]

8. López-Beceiro, J.; Díaz-Díaz, A.M.; Alvarez-García, A.; Tarrío-Saavedra, J.; Artiaga, R. The complexity of lignin thermal degradation in the isothermal context. Processes 2021, 9, 1154. [CrossRef]

9. Hu, J.; Song, Y.; Liu, J.; Evrendilek, F.; Buyukada, M.; Yan, Y.; Li, L. Combustions of torrefaction-pretreated bamboo forest residues: Physicochemical properties, evolved gases, and kinetic mechanisms. Bioresour. Technol. 2020, 304, 122960. [CrossRef]

10. Anca-Couce, A.; Obernberger, I. Application of a detailed biomass pyrolysis kinetic scheme to hardwood and softwood torrefaction. Fuel 2016, 167, 158-167. [CrossRef]

11. Magalhães, S.; Filipe, A.; Melro, E.; Fernandes, C.; Vitorino, C.; Alves, L.; Romano, A.; Rasteiro, M.; Medronho, B. Lignin Extraction from Waste Pine Sawdust Using a Biomass Derived Binary Solvent System. Polymers 2021, 13, 1090. [CrossRef]

12. Amaral, S.S.; de Carvalho, J.A., Jr.; Costa, M.A.M.; Neto, T.G.S.; Dellani, R.; Leite, L.H.S. Comparative study for hardwood and softwood forest biomass: Chemical characterization, combustion phases and gas and particulate matter emissions. Bioresour. Technol. 2014, 164, 55-63. [CrossRef] [PubMed]

13. Mian, I.; Li, X.; Dacres, O.D.; Wang, J.; Wei, B.; Jian, Y.; Zhong, M.; Liu, J.; Ma, F.; Rahman, N. Combustion kinetics and mechanism of biomass pellet. Energy 2020, 205, 117909. [CrossRef]

14. Kosowska-Golachowska, M.; Technology CUo Machinery, I.O.T. Thermal analysis and kinetics of coal during oxy-fuel combustion. J. Thermal Sci. 2017, 26, 355-361. [CrossRef]

15. Chen, R.; Li, Q.; Xu, X.; Zhang, D. Comparative pyrolysis characteristics of representative commercial thermosetting plastic waste in inert and oxygenous atmosphere. Fuel 2019, 246, 212-221. [CrossRef]

16. Toscano, G.; Duca, D.; Rossini, G.; Mengarelli, C.; Pizzi, A. Identification of different woody biomass for energy purpose by means of Soft Independent Modeling of Class Analogy applied to thermogravimetric analysis. Energy 2015, 83, 351-357. [CrossRef]

17. An, W.; Tang, Y.; Liang, K.; Cai, M.; Wang, T.; Wang, Z. Experimental study on downward flame spread characteristics under the influence of parallel curtain wall. Fractals 2019, 62, 102407. [CrossRef]

18. Weiguang, A.; Xiangwei, Y.; Minglun, C.; Yunji, G.; Hetang, W. Influence of vertical channel on downward flame spread over extruded polystyrene foam. Int. J. Thermal Sci. 2019, 145, 105991.

19. An, W.; Tang, Y.; Liang, K.; Cai, M.; Wang, T.; Wang, Z. Study on temperature distribution and CO diffusion induced by cable fire in L-shaped utility tunnel. Sustain. Cities Soc. 2020, 62, 102407. [CrossRef]

20. Ding, Y.; Huang, B.; Li, K.; Du, W.; Lu, K.; Zhang, Y. Thermal interaction analysis of isolated hemicellulose and cellulose by kinetic parameters during biomass pyrolysis. Energy 2020, 195, 117010. [CrossRef]

21. Polesek-Karczewska, S.; Kardaś, D. Prediction of thermal behavior of pyrolyzed wet biomass by means of model with inner wood structure. J. Therm. Sci. 2015, 24, 82-89. [CrossRef]

22. Ding, Y.; Fukumoto, K.; Ezekoye, O.; Lu, S.; Wang, C.; Li, C. Experimental and numerical simulation of multi-component combustion of typical charring material. Combust. Flame 2020, 211, 417-429. [CrossRef]

23. Yang, H.; Yan, R.; Chen, H.; Lee, D.H.; Zheng, C. Characteristics of hemicellulose, cellulose and lignin pyrolysis. Fuel 2007, 86, 1781-1788. [CrossRef]

24. Slopiecka, K.; Bartocci, P.; Fantozzi, F. Thermogravimetric analysis and kinetic study of poplar wood pyrolysis. Appl. Energy 2012, 97, 491-497. [CrossRef]

25. Dong, C.-Q.; Zhang, Z.-F.; Lu, Q.; Yang, Y.-P. Characteristics and mechanism study of analytical fast pyrolysis of poplar wood. Energy Convers. Manag. 2012, 57, 49-59. [CrossRef]

26. Zou, H.; Zhang, J.; Liu, J.; Buyukada, M.; Evrendilek, F.; Liang, G. Pyrolytic behaviors, kinetics, decomposition mechanisms, product distributions and joint optimization of Lentinus edodes stipe. Energy Convers. Manag. 2020, 213, 112858. [CrossRef]

27. Ding, Y.; Ezekoye, O.; Lu, S.; Wang, C.; Zhou, R. Comparative pyrolysis behaviors and reaction mechanisms of hardwood and softwood. Energy Convers. Manag. 2017, 132, 102-109. [CrossRef]

28. Yao, F.; Wu, Q.; Lei, Y.; Guo, W.; Xu, Y. Thermal decomposition kinetics of natural fibers: Activation energy with dynamic thermogravimetric analysis. Polym. Degrad. Stab. 2008, 93, 90-98. [CrossRef]

29. Echresh Zadeh, Z.; Abdulkhani, A.; Saha, B. Characterization of Fast Pyrolysis Bio-Oil from Hardwood and Softwood Lignin. Energies 2020, 13, 887. [CrossRef] 
30. Asmadi, M.; Kawamoto, H.; Saka, S. Characteristics of softwood and hardwood pyrolysis in an ampoule reactor. J. Anal. Appl. Pyrolysis 2017, 124, 523-535. [CrossRef]

31. Grønli, M.G.; Varhegyi, G.; Di Blasi, C. Thermogravimetric Analysis and Devolatilization Kinetics of Wood. Ind. Eng. Chem. Res. 2002, 41, 4201-4208. [CrossRef]

32. Gil, M.; Casal, D.; Pevida, C.; Pis, J.; Rubiera, F. Thermal behaviour and kinetics of coal/biomass blends during co-combustion. Bioresour. Technol. 2010, 101, 5601-5608. [CrossRef]

33. Kong, B.; Wang, E.; Li, Z.; Lu, W. Study on the feature of electromagnetic radiation under coal oxidation and temperature rise based on multi-fractal theory. Fractals 2019, 27, 1950038. [CrossRef]

34. Cai, P.; Nie, W.; Chen, D.; Yang, S.; Liu, Z. Effect of air flowrate on pollutant dispersion pattern of coal dust particles at fully mechanized mining face based on numerical simulation. Fuel 2019, 239, 623-635. [CrossRef]

35. Kissinger, H.E. Variation of peak temperature with heating rate in differential thermal analysis. J. Res. Natl. Inst. Stand. Technol. 1956, 57, 217. [CrossRef]

36. Akahira, T.; Sunose, T. Method of determining activation deterioration constant of electrical insulating materials. Sci. Technol. 1971, 16, 22-31.

37. Coats, A.W.; Redfern, J.P. Kinetic parameters from thermogravimetric data. Nature 1964, 201, 68-69. [CrossRef]

38. Xu, X.; Pan, R.; Li, P.; Chen, R. Kinetics, Thermodynamics, and Volatile Products of Camphorwood Pyrolysis in Inert Atmosphere. Appl. Biochem. Biotechnol. 2020, 1-19. [CrossRef]

39. Qiao, Y.; Das, O.; Zhao, S.-N.; Sun, T.-S.; Xu, Q.; Jiang, L. Pyrolysis Kinetic Study and Reaction Mechanism of Epoxy Glass Fiber Reinforced Plastic by Thermogravimetric Analyzer (TG) and TG-FTIR (Fourier-Transform Infrared) Techniques. Polymers 2020, 12, 2739. [CrossRef]

40. Jiang, H.; Wang, J.; Wu, S.; Wang, B.; Wang, Z. Pyrolysis kinetics of phenol-formaldehyde resin by non-isothermal thermogravimetry. Carbon 2010, 48, 352-358. [CrossRef]

41. Vlaev, L.; Nedelchev, N.; Gyurova, K.; Zagorcheva, M. A comparative study of non-isothermal kinetics of decomposition of calcium oxalate monohydrate. J. Anal. Appl. Pyrolysis 2008, 81, 253-262. [CrossRef]

42. Liqing, L.; Donghua, C. Application of iso-temperature method of multiple rate to kinetic analysis. J. Therm. Anal. Calorim. 2004 78, 283-293. [CrossRef]

43. Chen, R.; Li, Q.; Zhang, Y.; Xu, X.; Zhang, D. Pyrolysis kinetics and mechanism of typical industrial non-tyre rubber wastes by peak-differentiating analysis and multi kinetics methods. Fuel 2019, 235, 1224-1237. [CrossRef]

44. Wu, X.; Wei, Z.; Liu, J.; Chen, Z.; Huang, W. Oxy-fuel and air combustion performances and gas-to-ash products of aboveground and below ground biomass of Sedum alfredii Hance. Chem. Eng. J. 2021, 422, 130312. [CrossRef]

45. Jiang, L.; Zhang, D.; Li, M.; He, J.-J.; Gao, Z.-H.; Zhou, Y.; Sun, J.-H. Pyrolytic behavior of waste extruded polystyrene and rigid polyurethane by multi kinetics methods and Py-GC/MS. Fuel 2018, 222, 11-20. [CrossRef]

46. Vyazovkin, S.; Burnham, A.; Criado, J.M.; Perez-Maqueda, L.A.; Popescu, C.; Sbirrazzuoli, N. ICTAC Kinetics Committee recommendations for performing kinetic computations on thermal analysis data. Thermochim. Acta 2011, 520, 1-19. [CrossRef]

47. Cai, H.; Zou, H.; Liu, J.; Xie, W.; Kuo, J.; Buyukada, M.; Evrendilek, F. Thermal degradations and processes of waste tea and tea leaves via TG-FTIR: Combustion performances, kinetics, thermodynamics, products and optimization. Bioresour. Technol. 2018, 268, 715-725. [CrossRef] [PubMed]

48. Zhang, J.; Liu, J.; Evrendilek, F.; Xie, W.; Kuo, J.; Zhang, X.; Buyukada, M. Kinetics, thermodynamics, gas evolution and empirical optimization of cattle manure combustion in air and oxy-fuel atmospheres. Appl. Therm. Eng. 2019, 149, 119-131. [CrossRef]

49. Zou, H.; Evrendilek, F.; Liu, J.; Buyukada, M. Combustion behaviors of pileus and stipe parts of Lentinus edodes using thermogravimetric-mass spectrometry and Fourier transform infrared spectroscopy analyses: Thermal conversion, kinetic, thermodynamic, gas emission and optimization analyses. Bioresour. Technol. 2019, 288, 121481. [CrossRef]

50. Li, Q.; Zhao, C.; Chen, X.; Wu, W.; Li, Y. Comparison of pulverized coal combustion in air and in $\mathrm{O}_{2} / \mathrm{CO}_{2}$ mixtures by thermo-gravimetric analysis. J. Anal. Appl. Pyrolysis 2009, 85, 521-528. [CrossRef] 